\title{
Impact of Emulsifiers Addition on the Retrogradation of Rice Gels during Low-Temperature Storage
}

\author{
Zhe Yang, Xue Han, Huiying Wu, Lijuan Zhang, Lanwei Zhang, and M. Javed Iqbal \\ School of Chemical Engineering and Chemistry, Harbin Institute of Technology, Harbin, Heilongjiang 150090, China \\ Correspondence should be addressed to Xue Han; xhan@hit.edu.cn
}

Received 15 March 2017; Revised 29 June 2017; Accepted 20 July 2017; Published 21 November 2017

Academic Editor: Golfo Moatsou

Copyright (C) 2017 Zhe Yang et al. This is an open access article distributed under the Creative Commons Attribution License, which permits unrestricted use, distribution, and reproduction in any medium, provided the original work is properly cited.

\begin{abstract}
Rice and its products are widely consumed in Asian countries; however, starch retrogradation decreases the quality and shortens the shelf-life of rice foods particularly at low temperature. In this study sucrose ester (SE), glycerol monostearate (GMS), and sodium stearoyl lactylate (SSL) were added to rice flour and corresponding rice gels. Then, gelatinization properties, retrogradation characteristics, texture, and water content of these rice gels were investigated at $4{ }^{\circ} \mathrm{C}$ and $-20^{\circ} \mathrm{C}$ storage, respectively. The results demonstrated that the rice gels with $0.2 \%$ GMS had the lowest retrogradation index $\left(\Delta H_{r} / \Delta H_{g}\right)(11.84 \%)$ and hardness $(1359 \mathrm{~g})$ at $4^{\circ} \mathrm{C}$ for a $10 \mathrm{~d}$ period, which was significantly lower in comparison to control and the other two emulsifiers $(P<0.05)$. Adhesiveness and water content were increased compared to the other samples. Furthermore, the retrogradation of rice gels stored at $4^{\circ} \mathrm{C}$ was comparatively rapid compared to gels stored at $-20^{\circ} \mathrm{C}$. Gel samples stored at $-20^{\circ} \mathrm{C}$ were still acceptable for more than 15 days. Thus it was revealed that GMS has the potential to retard starch retrogradation and produce high-quality rice products in preservation.
\end{abstract}

\section{Introduction}

Rice sustains two-thirds of the world's population at present. Rice from northeast China possesses high nutritional value and good taste, based on consumers' preferences. However, during storage, several physicochemical and physiological changes occur in rice foods including loss of moisture and aroma, ultimately imparting firmness and cracking technically referred to as retrogradation [1]. Starch retrogradation is a process whereby when a gelatinized solution is cooled for a long time, it changes into a gel and rearranges itself into a crystalline structure. It is an unavoidable phenomenon affecting the texture and quality of many ready meals, including starchy rice foods $[2,3]$. Starch retrogradation severely affects the nutritional properties and storage stability of these products, seriously limiting the development of the food industry. Therefore, understanding the factors required to curtail retrogradation is of prior concern.

Various methods have been used to control starch retrogradation, namely, physical techniques (temperature, pressure, humidity, and storage conditions), the addition of food additives (emulsifier, hydrocolloids, and nonstarch polysaccharides), enzymolysis, and biotechnological modifications [4]. Among all food additives, emulsifiers have been widely used in delaying the retrogradation of bread and cake products [5]. Lai [6] reported that the addition of glycerol monostearate (GMS) and sucrose ester (SE) in rice starch formed a starch-emulsifier complex that stabilized the granule and delayed water penetration and swelling. Eduardo et al. [7] found that composite bread with a combination of hydrocolloids and emulsifiers had the lowest crumb firmness $(P<0.05)$, significantly reduced melting enthalpy values compared to the reference bread, and delayed melting of recrystallized amylopectin enthalpy. The antiretrogradation effect of emulsifiers depends on the ratio of amylose and amylopectin in starch $[2,8]$. In addition, the rice storage temperature, the water content, and other factors will also influence the result of emulsifiers.

Most of the researchers have tried controlling the temperature and water content along with other methods to inhibit the occurrence of rice retrogradation, but they are still unable to stop it. Research on the effect of emulsifiers on the retrogradation process of rice at low temperatures is also limited. The mechanism of how these surfactants 
influenced starch structure is not completely understood. Therefore, the objective of this study was to investigate the changes in the retrogradation index, textural properties, and water content at low temperatures $\left(4^{\circ} \mathrm{C}\right.$ and $\left.-20^{\circ} \mathrm{C}\right)$ during the whole storage process and compare the effect of different emulsifiers on rice starch, helping to elucidate the mechanism of antiretrogradation of emulsifiers. These results could provide some theoretical guidance for retarding the retrogradation of rice during its storage.

\section{Materials and Methods}

2.1. Sample Preparation. Rice (Zhongen Rice Industry Co., Ltd., Tianjin, China) was smashed through 100-mesh sieve. The starch content of rice was $67.10 \%$, as determined by the butyl-alcohol sedimentation method. $30.00 \mathrm{~g}$ of rice flour was weighed in each beaker, with $0.3 \%$ sucrose ester (SE), $0.2 \%$ sodium stearoyl lactylate (SSL), and $0.2 \%$ glycerol monostearate (GMS) (w/w) and allowed to be mixed completely. Water was added to obtain a ratio of 1:2 (rice/water; w/v). A sample without an emulsifier was used as the control. These samples were then immersed in a hot bath $\left(90^{\circ} \mathrm{C}\right)$ for $30 \mathrm{~min}$ with subsequent refrigeration and freezing at $4^{\circ} \mathrm{C}$ and $-20^{\circ} \mathrm{C}$ for a $1,3,5,7,10$, and 13 and 1, 3, 5, 10, 15, and 30 days of storage, respectively.

2.2. Gelatinization Properties Determination. Gelatinization properties were determined by DSC (Pyris 6 DSC, PerkinElmer, USA). It was performed according to Tao et al. [9] with some modification. Approximately $4 \mathrm{mg}$ samples were weighed and distilled water was added to obtain a starch-to-water ratio of $1: 2(\mathrm{w} / \mathrm{w})$, and the samples were hermetically sealed. Pans were kept for $10 \mathrm{~h}$ at $25^{\circ} \mathrm{C}$ and then heated from $20^{\circ} \mathrm{C}$ to $140^{\circ} \mathrm{C}$ at $10^{\circ} \mathrm{C} / \mathrm{min}$ (empty pan as reference). From the thermograms, the gelatinization enthalpy $\left(\Delta H_{g}\right)$, onset temperature $\left(T_{o}\right)$, peak temperature $\left(T_{p}\right)$, and conclusion temperature $\left(T_{c}\right)$ were obtained after the first heating run. Then, the gelatinized rice samples (in the originally sealed pan) were stored at $4^{\circ} \mathrm{C}$ or $-20^{\circ} \mathrm{C}$ for $1,3,5,10,15$, and 20 days, respectively, for retrogradation research.

2.3. Retrogradation Properties Determination. The above stored samples were thawed at room temperature $\left(25 \pm 2^{\circ} \mathrm{C}\right)$ for $5 \mathrm{~h}$ before being scanned again using DSC with the same heating program above to obtain the retrogradation enthalpy $\left(\Delta H_{r}\right)$. The peak areas at $40-70^{\circ} \mathrm{C}$ were calculated as $\Delta \mathrm{H}_{r}$. The retrogradation index $\left(\Delta H_{r} / \Delta H_{g}\right)$ was defined as the ratio between retrogradation $\left(\Delta H_{r}\right)$ and the gelatinization enthalpy $\left(\Delta H_{g}\right)[10]$.

2.4. Textural Analysis. A textural analysis of rice gels was performed according to Xia et al. [11] with some modification. Texture profile of the samples was determined by Texture Analyzer TA-XT 2 (Stable Micro Systems, Surrey GU7 1YL, $\mathrm{UK}$ ). The rice gels (thickness of $2 \mathrm{~cm}$, the diameter of $5 \mathrm{~cm}$ ) were arranged on a platform. By compressing the samples with a probe $(\mathrm{P} / 50)$ using a test speed of $0.5 \mathrm{~mm} / \mathrm{s}$ and posttest speed of $0.5 \mathrm{~mm} / \mathrm{s}$, the deformation level was $40 \%$ of the original sample height when the gels were compressed twice. Textural parameters (i.e., hardness and adhesiveness) were determined via Texture Expert software 3.2.

2.5. Water Content Determination. The rice gels were weighed (3-4 g) in a weighing pan having a glass cover and placed in a hot air oven at $100-105^{\circ} \mathrm{C}$. After $2-3 \mathrm{~h}$, samples were taken out and weighed again until constant weight was obtained. The water content is the ratio between the weight difference and initial weight.

2.6. Statistical Analysis. Statistical analyses were performed using SPSS 12.0 software (SPSS Inc.; Chicago, IL, USA). Significant differences among treatments were tested by ANOVA followed by Tukey's test $(P<0.05)$. Data were expressed as the mean values \pm standard error (SE). All the analyses were performed in a triplicate run. Data were expressed as the mean values \pm standard error (SE).

\section{Results}

3.1. Gelatinization Properties. The gelatinization parameters of rice gels with different emulsifiers were shown in Table 1. The range of gelatinization temperatures (onset temperature $\left(T_{o}\right)$, peak temperature $\left(T_{p}\right)$, and conclusion temperature $\left(T_{c}\right)$ ) for all samples was approximately $60-80^{\circ} \mathrm{C}$, and $T_{o}$ was approximately $60^{\circ} \mathrm{C}$. Compared to the control, values of $T_{p}$ and $T_{c}$ were significantly increased by the addition of $0.2 \%$ GMS $(P<0.05)$. $T_{o}$ and $\Delta H_{g}$ were not significantly different among the rice gels with and without the addition of emulsifiers $(P>0.05)$. Adding SE and SSL could increase $\Delta H_{g}$ values while adding GMS decreased $\Delta H_{g}$. These results suggested that $0.2 \%$ GMS could reduce the gelatinization temperature $\left(\Delta H_{g}\right)$.

3.2. Retrogradation Properties. Figure 1 showed the retrogradation index $\left(\Delta H_{r} / \Delta H_{g}\right)$ of rice gels stored at $4^{\circ} \mathrm{C}$ and $-20^{\circ} \mathrm{C}$. With the advancement in storage time prolonged, $\Delta H_{r} / \Delta H_{g}$ was increased gradually, which indicated retrogradation of rice gel was more obvious. Compared to the control, the $\Delta H_{r} / \Delta H_{g}$ values of the samples with emulsifiers significantly decreased at $4^{\circ} \mathrm{C}$ in Figure 1(a). The rice gels with $0.2 \%$ added GMS exhibited no significant change in $\Delta H_{r} / \Delta H_{g}$ during the first 10 days $(11.84 \%)(P>0.05)$, whereas at 20 th days of storage they declined by $30 \%$ compared to the control samples thus affirming GMS as an antiaging emulsifier inhibiting the rice starch retrogradation.

The results from Figure 1(b) showed that there was no significant difference in $\Delta H_{r} / \Delta H_{g}$ value between the control and emulsifiers at $-20^{\circ} \mathrm{C}(P>0.05)$. It was observed that adding of emulsifiers in rice gels certainly changed the retrogradation trend in these gels in comparison to the control samples. At the 20th day of storage the $\Delta H_{r} / \Delta H_{g}$ values for GMS (32.19\%) and SE (31.21\%) were lower than control when stored at $-20^{\circ} \mathrm{C}$. Furthermore, regarding the retrogradation index, rice gels stored at $4^{\circ} \mathrm{C}$ had higher values 
TABLE 1: Gelatinization properties of rice gels with different emulsifiers (means $\pm \mathrm{SE}$ ).

\begin{tabular}{lcccc}
\hline Sample type & $T_{o}\left({ }^{\circ} \mathrm{C}\right)$ & $T_{p}\left({ }^{\circ} \mathrm{C}\right)$ & $T_{c}\left({ }^{\circ} \mathrm{C}\right)$ & $\Delta H_{g}(\mathrm{~J} / \mathrm{g})$ \\
\hline Control & $62.47 \pm 0.33^{\mathrm{a}}$ & $68.61 \pm 0.16^{\mathrm{a}}$ & $75.34 \pm 0.22^{\mathrm{a}}$ & $6.89 \pm 0.04^{\mathrm{a}}$ \\
$0.3 \%$ SE & $62.54 \pm 0.50^{\mathrm{a}}$ & $69.08 \pm 0.10^{\mathrm{ab}}$ & $76.06 \pm 0.10^{\mathrm{ab}}$ & $7.91 \pm 0.35^{\mathrm{a}}$ \\
$0.2 \%$ SSL & $62.60 \pm 0.16^{\mathrm{a}}$ & $69.52 \pm 0.16^{\mathrm{ab}}$ & $76.51 \pm 0.28^{\mathrm{bc}}$ & $7.55 \pm 0.30^{\mathrm{a}}$ \\
$0.2 \%$ GMS & $63.31 \pm 0.41^{\mathrm{a}}$ & $70.13 \pm 0.57^{\mathrm{b}}$ & $76.99 \pm 0.19^{\mathrm{c}}$ & $6.70 \pm 0.76^{\mathrm{a}}$ \\
\hline
\end{tabular}

Significant differences in each column were expressed as different letters $(P<0.05) . T_{o}, T_{p}$, and $T_{c}$ were the gelatinization temperatures of the onset, peak, and conclusion, respectively. $\Delta H_{g}$ was the enthalpy change of gelatinization.

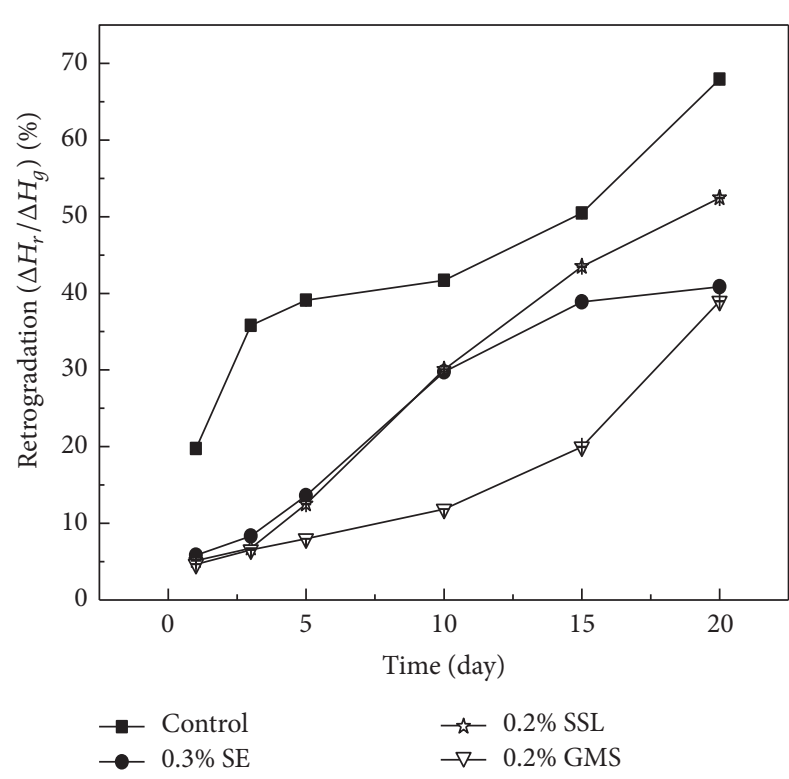

(a)

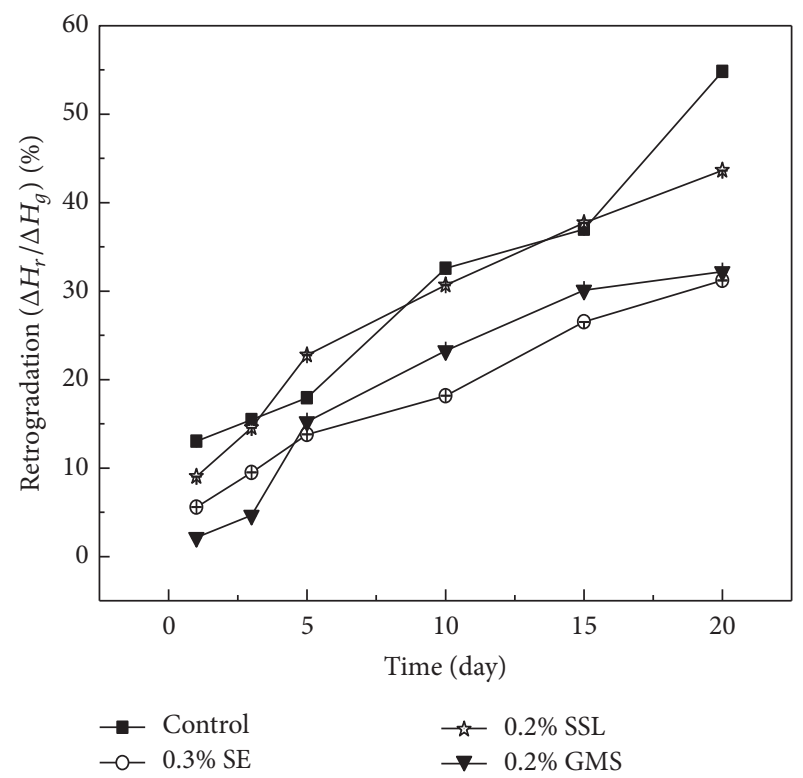

(b)

FIGURE 1: Retrogradation index $\left(\Delta H_{r} / \Delta H_{q}\right)$ of rice gels with different days of storage at $4^{\circ} \mathrm{C}(\mathrm{a})$ and $-20^{\circ} \mathrm{C}(\mathrm{b})$. Error bars indicate standard error.

than that stored at $-20^{\circ} \mathrm{C}$. Thus, the temperature of $-20^{\circ} \mathrm{C}$ could effectively retard the retrogradation of samples. In conclusion, $0.2 \%$ GMS showed a lower rate of retrogradation during the 10 days at $4^{\circ} \mathrm{C}$, and the $\Delta H_{r} / \Delta H_{g}$ values $(11.84 \%)$ were within the satisfactory range.

3.3. Textural Properties. The hardness and adhesiveness of rice gels at different storage times were illustrated in Figure 2. During storage of samples at 4 and $-20^{\circ} \mathrm{C}$, the hardness was gradually increased, whereas the adhesiveness was gradually decreased. In combination with the retrogradation index, it was found that $\Delta H_{r} / \Delta H_{g}$ values were positively correlated with hardness and negatively correlated with adhesiveness (Figures 1 and 2). Similar changes were also reported on waxy and normal corn starch gels retrogradation through controlled freezing rate [12]. In Figures 2(a) and 2(b), the changing rate of hardness and adhesiveness of $0.2 \%$ GMS was the lowest at $4^{\circ} \mathrm{C}$. For hardness, a slight increase was observed during the first 10 days of $0.2 \%$ GMS (1359 g), followed by a noticeable increase throughout the storage period.

In Figure 2(c), the sample with the addition of $0.2 \%$ GMS had the lowest hardness values at the same storage time at $-20^{\circ} \mathrm{C}$. However, there was a sharp increase of almost $76 \%$ in the first 15 days, with a further steady increase up to $3111.47 \mathrm{~g}$ at the 30 days of storage. Rice gels showed a steady increase in hardness with gradual decrease in adhesiveness during the first 12 days when stored at $-20^{\circ} \mathrm{C}$, reaching an asymptote after that. The adhesiveness of rice gels with $0.3 \%$ SE (-222.04 g.s) and 0.2\% GMS (-204.23 g.s) was similar at the 30 days of storage at $-20^{\circ} \mathrm{C}$ (Figure 2(d)). Therefore, compared to the control, rice gels with $0.2 \%$ GMS had lower hardness and higher adhesiveness during the 10 days at $4^{\circ} \mathrm{C}$. GMS exhibited better textural properties than SE and SSL. From Figure 2, it can also be seen that $-20^{\circ} \mathrm{C}$ can extend the storage time of rice gels by at least 15 days compared to $4^{\circ} \mathrm{C}$.

3.4. Water Content. Changes in the water content of rice gels during storage were illustrated in Figure 3. As the storage time proceeds, the water content of samples was reduced gradually at $4^{\circ} \mathrm{C}$ and $-20^{\circ} \mathrm{C}$. Compared to the control, rice with the addition of emulsifier had greater water content when stored at $4^{\circ} \mathrm{C}$. As shown in Figure 3(a), there was no significant difference among the three emulsifiers $(P>0.05)$. During storage at $4^{\circ} \mathrm{C}$, the sample with GMS addition has the highest water content than the other samples (Figure 3(a)). On the other hand, at $-20^{\circ} \mathrm{C}$, the sample with 


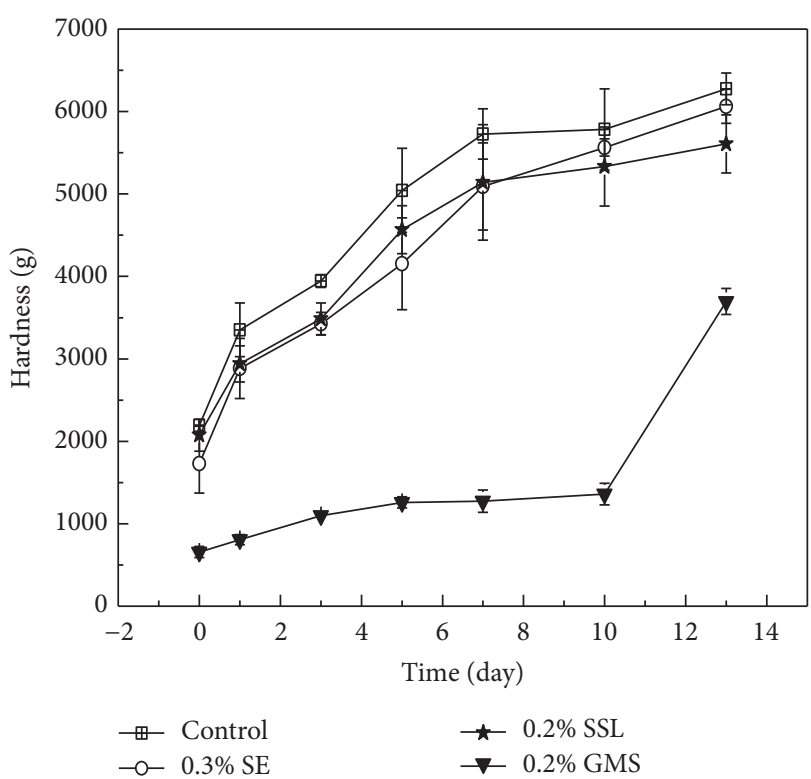

(a)

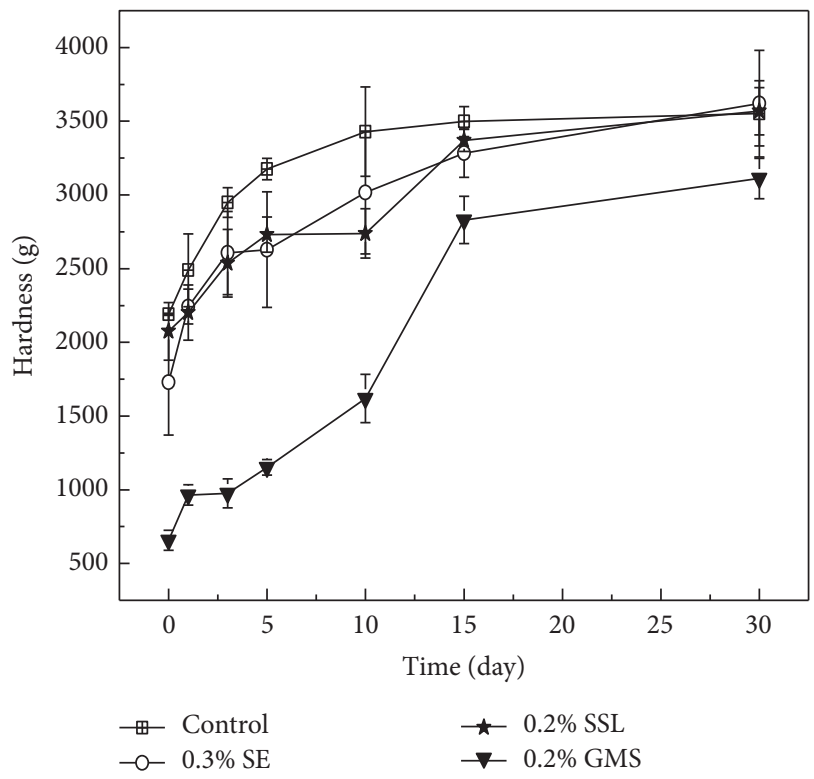

(c)

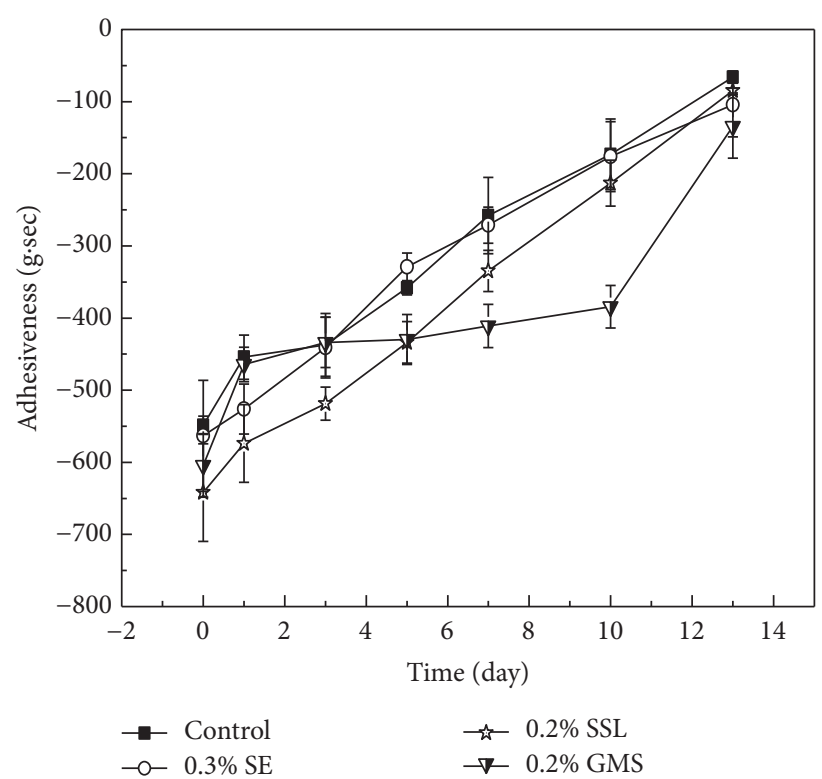

(b)

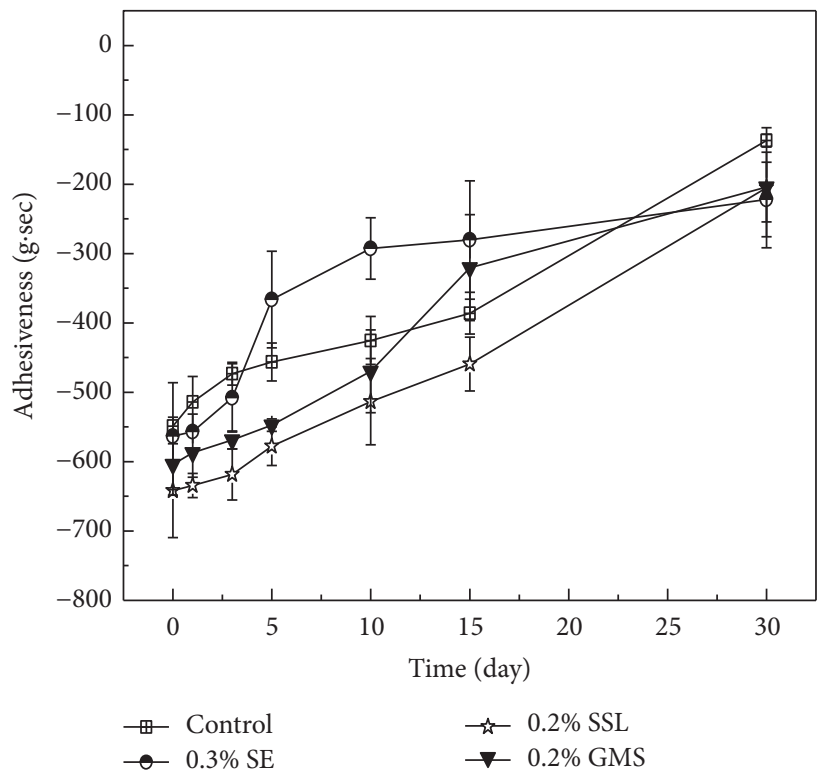

(d)

Figure 2: Hardness and adhesiveness of rice gels with different time storage at $4^{\circ} \mathrm{C}((\mathrm{a}),(\mathrm{b}))$ and $-20^{\circ} \mathrm{C}((\mathrm{c})$, (d)). Error bars indicate standard error.

SE addition had the highest water content (Figure 3(b)). Since retrogradation mainly occurred at $4^{\circ} \mathrm{C}$ and because the sample with GMS addition had lower hardness, adhesiveness, and retrogradation index than the samples with the other emulsifiers addition at $4^{\circ} \mathrm{C}$ storage, we choose GMS as a suitable antiretrogradation emulsifier.

\section{Discussion}

$0.2 \%$ GMS offered better antiretrogradation abilities than the control (Table 1 and Figure 1). GMS could be combined with starch molecules decreasing the starch crystallization rate, resulting in prolongation of the retrogradation process at lower temperature [13]. Some researchers have reported that rapid associations of amylose molecules are considered to dominate starch retrogradation during the first days (several hours or more than ten hours) after gelatinization. Furthermore, GMS has the lipophilicity of an emulsifier with a nonpolar group. Hydrophobic groups on GMS were plugged into the alpha-helix structure of gelatinized amylose and combined with starch forming strong stable amyloselipid complexes, thereby decreasing and preventing rapid retrogradation of amylose during the first 5 days of storage $[4,14]$. 


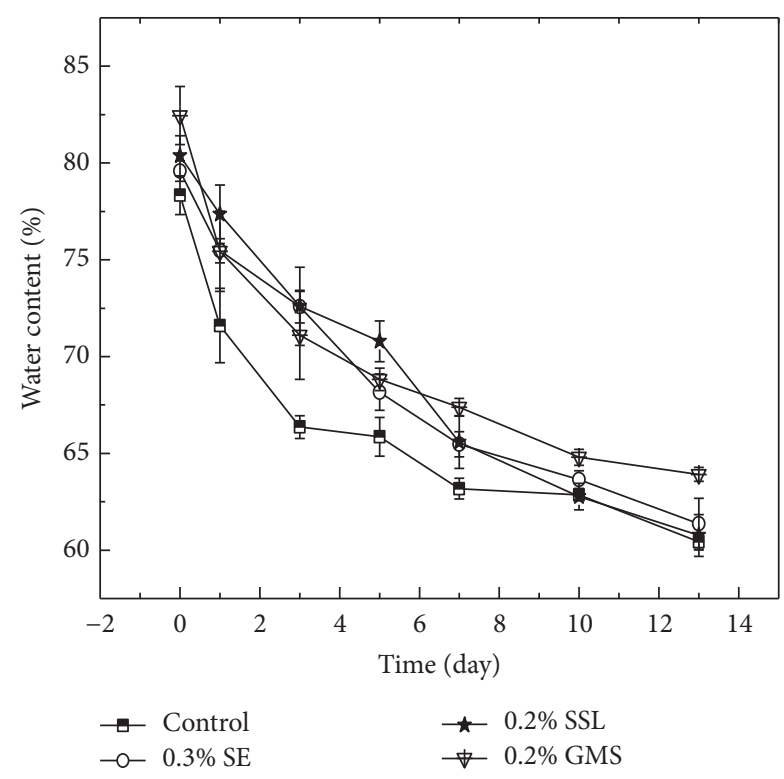

(a)

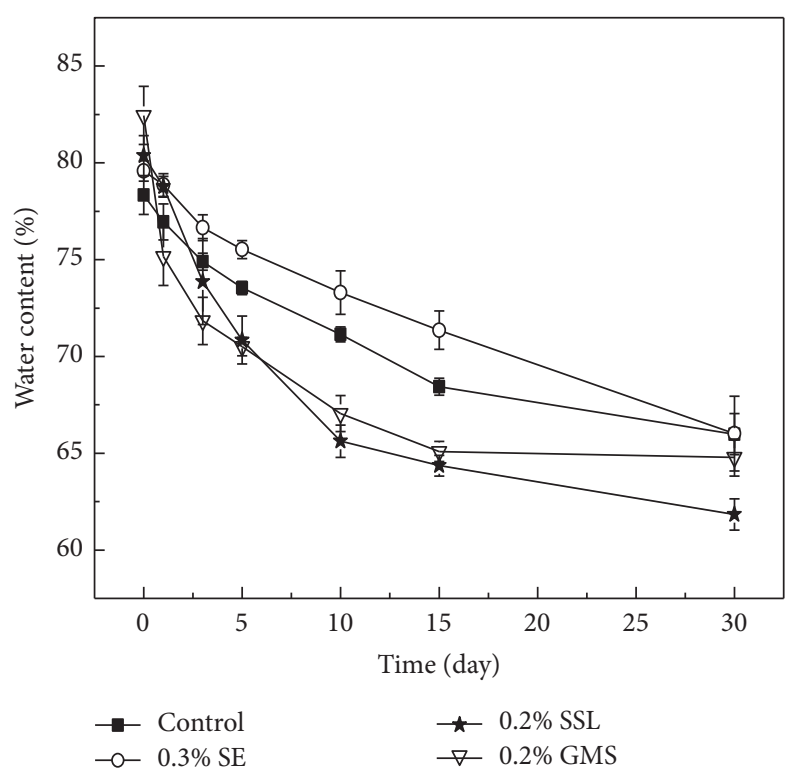

(b)

FIgURE 3: Water content of rice gels at different times of storage at $4^{\circ} \mathrm{C}$ (a) and $-20^{\circ} \mathrm{C}$ (b). Error bars indicate standard error.

Al-Hajji et al. [14] reported that, during prolonged storage time (one to seven weeks), retrogradation mainly occurs in amylopectin. In our research the amylose content of rice was $10.43 \%$ and amylopectin was $89.57 \%$. Thus, retrogradation may be mainly determined by amylopectin. As GMS could adhere to the surface of amylopectin and change the water distribution, interaction with the forked chain via hydrogen bonding was altered, reducing the water binding capacity of starch and ultimately indirectly delaying the long-term retrogradation [15]. In our research, the water content of adding GMS was higher than control (Figure 3). The other researchers showed that amylose-lipid complex resulted in the formation of single helical V-amylose complex. It had the capability to act as nuclei for retrogradation by cocrystallizing with amylopectin, affecting amylopectin recrystallization indirectly, and to some extent interfering with amylopectin retrogradation [13].

Retrogradation of rice starch during storage had a direct effect on the texture of rice gels. In our previous study, it was shown that the higher retrogradation index had higher hardness and lower adhesiveness. Adding emulsifier could improve the texture and decrease retrogradation index of rice gels. The texture of rice gels with SSL and SE addition was less better than GMS. As SSL and SE were all negatively charged emulsifiers, so they could repulse and prevent the strong association of amylose-lipid complexes [16]. Therefore, hardness level of samples in which SSL and SE were added changed more quickly than those in the presence of GMS (Figure 2(a)). Since GMS is the hydrophobic emulsifier its lipophilic moieties were attached to the nonpolar side chains of the protein complexes forming an intermolecular matrix via hydrogen bonding and proteins cross-linkages that resulted in reduced hardness [17].
The retrogradation index and texture of rice gels stored in $-20^{\circ} \mathrm{C}$ were better than those stored in $4^{\circ} \mathrm{C}$. That means the low temperatures and ultralow temperatures could delay starch retrogradation and maintain the textural properties of rice during the freezing process. The recrystallization of amylopectin was strongly dependent on the temperature, and the rate of nucleation was faster at $4^{\circ} \mathrm{C}[3]$.

Water plays a critical role in starch gels. The water content defines the extent of the granular form. Slade and Levine [18] reported the decrease in free water of bread with an increase in bound water content under storage. Free water can promote the migration of the starch molecules, while chemically bound water affected the formation of starch recrystallization crystals $[19,20]$. In our research, the sample with GMS addition had the higher keeping water ability. It may be because GMS could complex with amylose and prevent the leaching of amylose and increased binding free water capacity [6]. Figures 1 and 3 showed that when water content (free water) decreased, the retrogradation index of rice gels increased. Zhou et al. [21] confirmed that, with water contents of $80 \%$ and $90 \%$, no amylopectin crystallization was observed. However, with $60 \%$ and $70 \%$ water, there was amylopectin crystallization. This may be because when the water content was low, migration of starch molecules was difficult, and when the water content was high, it was easy for starch molecules to migrate due to the decrease of the starch concentration, and the chance of starch cross-linking and polymerization decreased. But when water content was below $70 \%$, all samples' retrogradation index was increased greatly except the sample with GMS addition (Figure 1). It was reported that when the water content was $60 \%$, the rate of long-term retrogradation was the highest [22]. Our research had verified these results. Therefore, it was necessary 
to change the water activity of the starch-water system to control the starch retrogradation by adding surfactants and other substances [15].

\section{Conclusions}

Emulsifiers are known to influence the gelatinization and retrogradation of rice starch. In this study, the addition of $0.2 \%$ GMS could decrease the gelatinization enthalpy $\left(\Delta H_{g}\right)$, retrogradation index, and hardness and increase the adhesiveness and water content. In particular, in rice gels stored at $4^{\circ} \mathrm{C}$ for a period of 10 days, $\Delta H_{r} / \Delta H_{g}$ values and hardness were reduced by $30 \%$ and $76 \%$, respectively, compared to the control, while adhesiveness and water content increased to $120 \%$ and 3\%, respectively. Furthermore, samples stored at $-20^{\circ} \mathrm{C}$ had a lower degree of retrogradation compared to those stored at $4^{\circ} \mathrm{C}$. These results implied that GMS could as a potential antiretrogradation agent retard starch retrogradation during low-temperature storage. This work could provide the theoretical guidance for slowing the retrogradation of starch.

\section{Additional Points}

Practical Applications. Rice starch retrogradation phenomenon is accredited for lowering quality and shelf-stability of ricebased food products. Keeping mentioned concern in view, this study was intensive to evaluate the effect of different emulsifiers on antiaging and preservation of rice gels under low-temperature storage. The results showed $0.2 \%$ GMS had a good antiaging ability and can keep the texture of rice gel. Furthermore in $4^{\circ} \mathrm{C}$ storage the retrogradation of rice was faster than that at $-20^{\circ} \mathrm{C}$. A temperature of $-20^{\circ} \mathrm{C}$ could extend the storage period for more than 15 days. Thus GMS has the potential to retard starch retrogradation and produce high-quality rice products in preservation.

\section{Conflicts of Interest}

The authors have declared no conflicts of interest.

\section{Acknowledgments}

This work was financially supported by the Hei Long Jiang Applied Technology Research and Development Project (GA14B201).

\section{References}

[1] W. Sang, X. Shao, and Z. T. Jin, “Texture attributes, retrogradation properties and microbiological shelf life of instant rice cake," Journal of Food Processing and Preservation, vol. 39, no. 6, pp. 1832-1838, 2015.

[2] M. Tako, Y. Tamaki, T. Teruya, and Y. Takeda, “The principles of starch gelatinization and retrogradation," Journal of Food and Nutrition Sciences, vol. 5, no. 3, pp. 280-291, 2014.

[3] S. Yu, Y. Ma, and X.-Q. Zheng, "Effects of low- and ultralowtemperature freezing on retrogradation and textural properties of rice starch gel during storage," Journal of Texture Studies, vol. 43, no. 3, pp. 175-186, 2012.

[4] Z. Fu, J. Chen, S.-J. Luo, C.-M. Liu, and W. Liu, "Effect of food additives on starch retrogradation: A review," Starch - Stärke, vol. 67, no. 1-2, pp. 69-78, 2015.

[5] A. Rohman, Y. B. C. Man, and E. Noviana, "Analysis of emulsifier in food using chromatographic techniques," J. Food Pharm. Sci, vol. 76, pp. 1017-1026, 2013.

[6] H.-M. Lai, "Effects of rice properties and emulsifiers on the quality of rice pasta," Journal of the Science of Food and Agriculture, vol. 82, no. 2, pp. 203-216, 2002.

[7] M. Eduardo, U. Svanberg, and L. Ahrné, "Effect of hydrocolloids and emulsifiers on the shelf-life of composite cassava-maizewheat bread after storage," Food Science \& Nutrition, vol. 4, no. 4, pp. 636-644, 2016.

[8] K. Huaisan, J. Uriyapongson, P. Rayas-Duarte, I. Alli, and V. Srijesdaruk, "Effect of food additives on rheological and textural properties of frozen high amylose rice starch gels," International Journal of Food Properties, vol. 12, no. 1, pp. 145-161, 2009.

[9] H. Tao, B. Zhang, F. Wu, Z. Jin, and X. Xu, "Effect of multiple freezing/thawing-modified wheat starch on dough properties and bread quality using a reconstitution system," Journal of Cereal Science, vol. 69, pp. 132-137, 2016.

[10] S. Sittipod and Y.-C. Shi, "Changes of starch during parboiling of rice kernels," Journal of Cereal Science, vol. 69, pp. 238-244, 2016.

[11] W. Xia, C. Liu, S. Luo, X. Xu, and G. Fu, "Effect of low temperature on the retrogradation behavior of rice gels with different milling degrees," Starch-Stärke, vol. 67, no. 11-12, pp. 1044-1052, 2015.

[12] S. Yu, Y. Ma, and D.-W. Sun, "Effects of freezing rates on starch retrogradation and textural properties of cooked rice during storage," LWT-Food Science and Technology, vol. 43, no. 7, pp. 1138-1143, 2010.

[13] J. A. Putseys, L. Lamberts, and J. A. Delcour, "Amyloseinclusion complexes: Formation, identity and physico-chemical properties," Journal of Cereal Science, vol. 51, no. 3, pp. 238-247, 2010.

[14] L. Al-Hajji, V. Nassehi, and A. Stapley, "Spatial variation of starch retrogradation in Arabic flat bread during storage," Journal of Food Engineering, vol. 187, pp. 44-52, 2016.

[15] S. Wang, C. Li, L. Copeland, Q. Niu, and S. Wang, "Starch retrogradation: a comprehensive review," Comprehensive Reviews in Food Science and Food Safety, vol. 14, no. 5, pp. 568-585, 2015.

[16] T. M. Ali and A. Hasnain, "Effect of emulsifiers on complexation and retrogradation characteristics of native and chemically modified White sorghum (Sorghum bicolor) starch," StarchStärke, vol. 65, pp. 490-498, 2013.

[17] J. A. López-Tenorio, E. Rodríguez-Sandoval, and J. U. Sepúlveda-Valencia, "The influence of different emulsifiers on the physical and textural characteristics of gluten-free cheese bread," Journal of Texture Studies, vol. 46, no. 4, pp. 227-239, 2015.

[18] L. Slade and H. Levine, "Beyond water activity: recent advances based on an alternative approach to the assessment of food quality and safety," Physical Review Letters, vol. 94, pp. 18-32, 2005.

[19] S. Y. Ma, D. M. Fan, L. Y. Wang, H. Z. Lian, J. X. Zhao, and H. Zhang, "Impact of microwave heating on the water state and distribution of potato starch granules," Modern Food Science and Technology, vol. 31, pp. 219-225, 2015. 
[20] L. Chen, Y. Tian, Q. Tong, Z. Zhang, and Z. Jin, "Effect of pullulan on the water distribution, microstructure and textural properties of rice starch gels during cold storage," Food Chemistry, vol. 214, pp. 702-709, 2017.

[21] X. Zhou, R. Wang, S.-H. Yoo, and S.-T. Lim, "Water effect on the interaction between amylose and amylopectin during retrogradation," Carbohydrate Polymers, vol. 86, no. 4, pp. 16711674, 2011.

[22] V. Derycke, G. E. Vandeputte, R. Vermeylen et al., "Starch gelatinization and amylose-lipid interactions during rice parboiling investigated by temperature resolved wide angle $\mathrm{X}$ ray scattering and differential scanning calorimetry," Journal of Cereal Science, vol. 42, no. 3, pp. 334-343, 2005. 

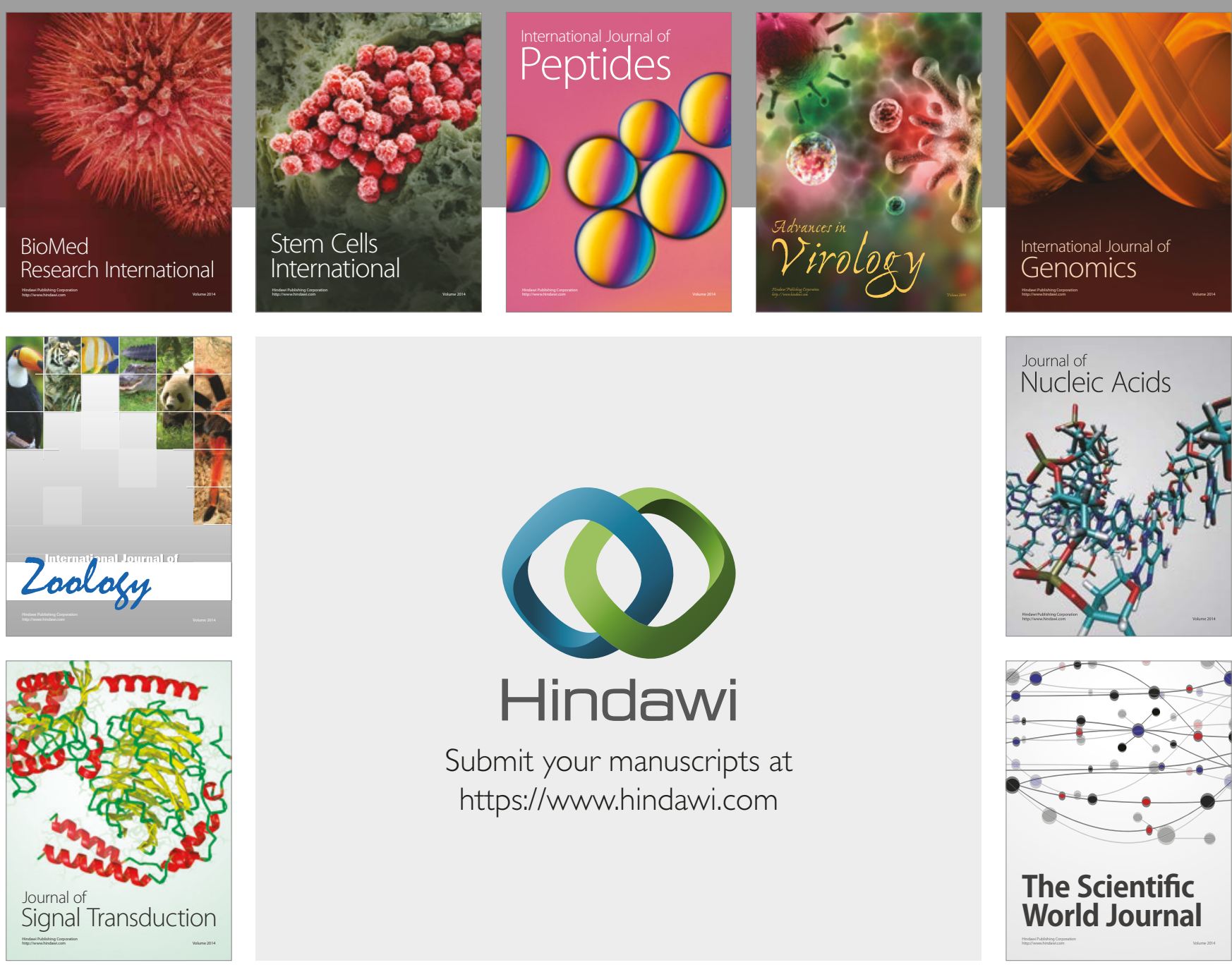

Submit your manuscripts at

https://www.hindawi.com
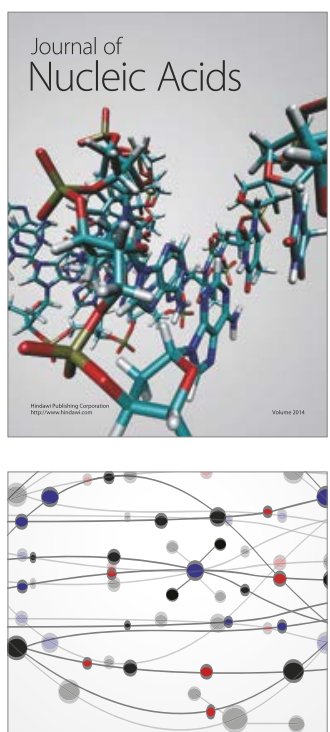

The Scientific World Journal

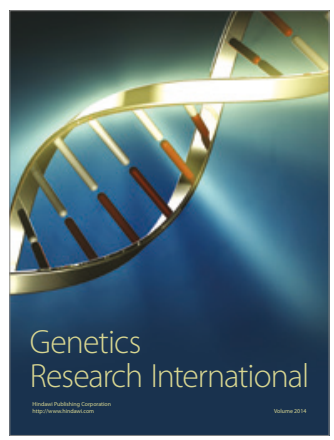

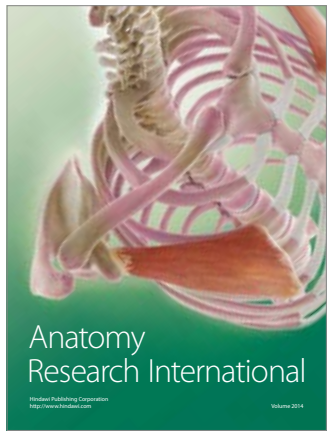

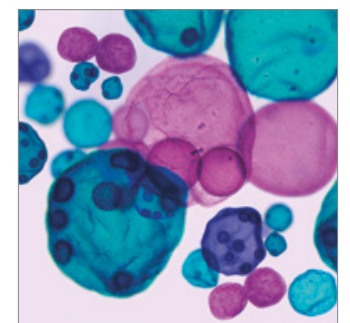

International Journal of Microbiology
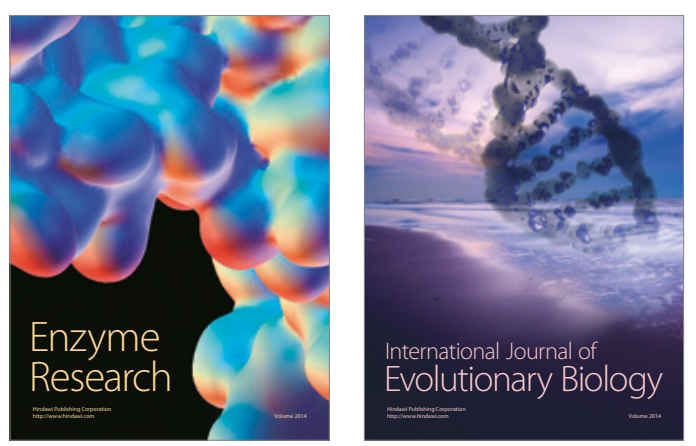
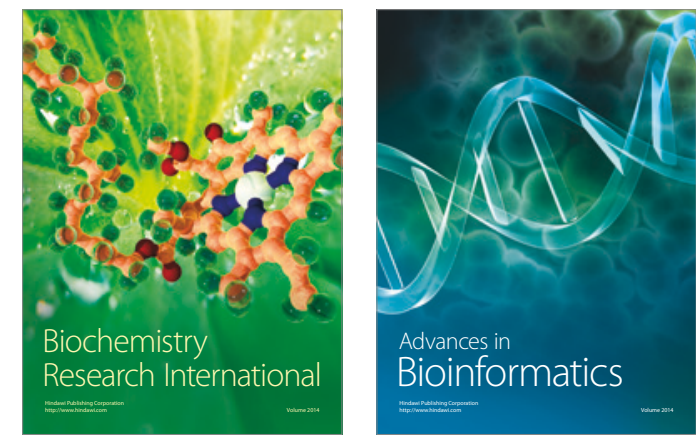

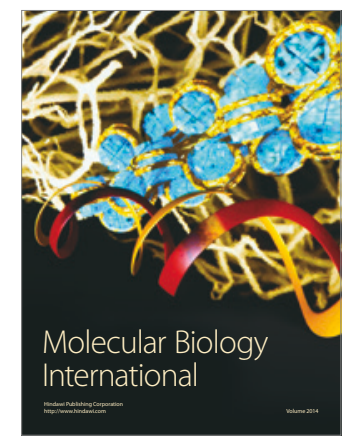

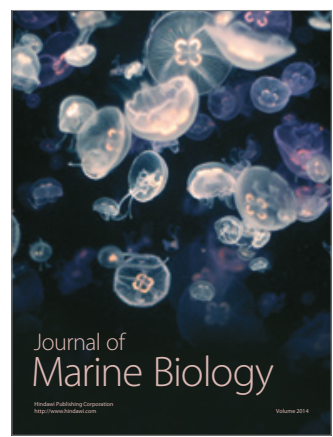

